\title{
Distal Biceps Brachii Tendon Ruptures (About a Case and Review of the Literature)
}

Smail Abdouli ${ }^{1,2 *}$, Rony Melhem ${ }^{1}$, Moctar Ould Moctar Neche ${ }^{2}$, Mohammed Elidrissi ${ }^{2}$, Abdelhalim Elibrahimi ${ }^{2}$, Abdelmajid Elmrini ${ }^{2}$

${ }^{1}$ Orthopedic Department, Rene-Dubos Hospital Center, 95300 Pontoise, France

${ }^{2}$ Orthopedic Department, UHC HassanII, University Sidi Mohmmed Ben Abdellah, 3000 fez, Morocco

DOI: $10.36347 /$ sasjs.2020.v06i05.006

| Received: 07.10.2019 | Accepted: 14.10.2019 | Published: 21.05.2020

*Corresponding author: Smail Abdouli

Abstract

We report a 41-year-old patient with distal biceps tendon rupture following direct trauma to the elbow. The patient benefited of large anterior approach surgical treatment with anatomical reinsertion by a thread mounted on a screw anchor.

Keywords: Rupture, Distal biceps tendon, single anterior approach.

Copyright @ 2020: This is an open-access article distributed under the terms of the Creative Commons Attribution license which permits unrestricted use, distribution, and reproduction in any medium for non-commercial use (NonCommercial, or CC-BY-NC) provided the original author and source are credited.

\section{INTRODUCTION}

Ruptures of the biceps tendon are rare, explaining that it can go unnoticed initially when the patient describes a mechanism without direct trauma such as a simple resisted movement or when the pain is not intense, clinical examination doesn't orient the diagnosis and X-rays are normal initially; the cause is almost always traumatic. Clinical signs are an acute pain of the elbow joint, associated with a loss of muscle strength and signs of muscle retraction. Confirmation of diagnosis is brought by ultrasound or MRI. Treatment is surgical, followed by a short immobilization, then an appropriate rehabilitation, we report a case of rupture of the distal biceps tendon following a direct trauma on an actively bent elbow treated surgically.

\section{CLINICAL CASE}

This is a 44-year-old computer scientist with no significant medical surgical history who received a blunt shock to the left elbow by a hockey stick on the ice, the patient felt a very intense pain on the anterior face of the elbow. Clinical examination revealed a tendon gap in the elbow with decreased supination strength with severe loss of bending force of the elbow, as well as an ascent of the left brachial biceps (Fig. 1). Standard X-rays were normal (Fig. 2). An ultrasound confirmed the diagnosis of rupture of the distal tendon of the brachial biceps with proximal retraction, the surgical procedure was performed under general anesthesia by a single skin incision (Fig. 3), addressing the anterior region of the elbow. The gesture consisted in isolating the retracted tendon and then attaching it to the bicipital tuberosity of the radius by a wire mounted on a screw anchor (Fig. 4). The surgical intervention was followed by immobilization in an above elbow posterior splint for four weeks and rehabilitation was started in the first week with isometric muscle activation, rehabilitation and Passive and active mobilisation as soon as the splint was removed, at nine months of the procedure, the patient had no pain, had regained normal and symmetrical muscle strength, especially in supination, and had resumed his work since the sixth post-operative months.

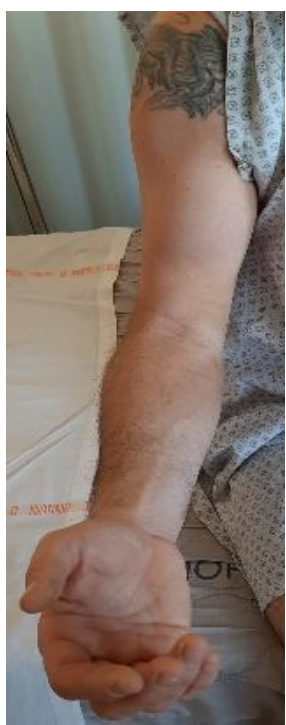

Fig-1: clinical image showed the ascent of the left brachial biceps 


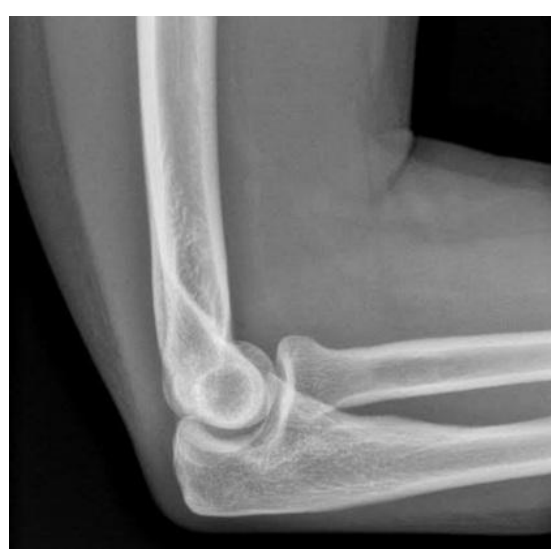

Fig-2: normal elbow radiograph

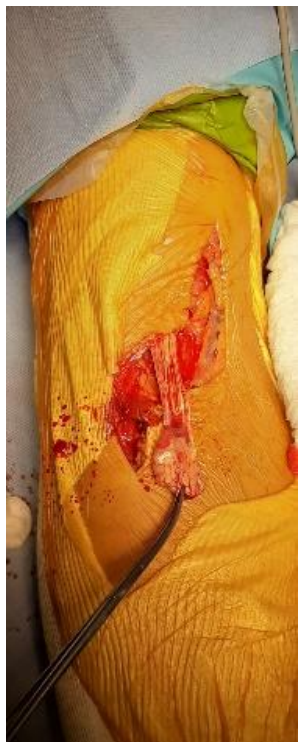

Fig-3: Intraoperative image showing isolation of the tendon

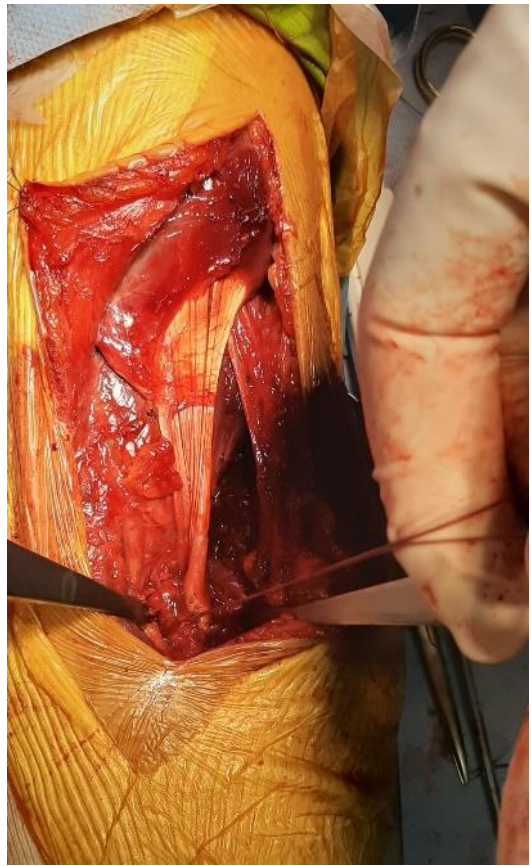

Fig-4: Intraoperative image showing the tendon attached by screw anchor

\section{DISCUSSION}

Biceps tendon fractures account for $3 \%$ of biceps lesions, they usually affect the dominant upper extremity, with an incidence of 1.2 per 100000 [1]. The usual susceptible population in whom the biceps tendon rupture occurs is a man aged 30 to 60 years old. The most commonly affected limb is the dominant limb, and smoking has been implicated as a risk factor, multiplying by 7 the risk of rupture of the distal tendon of the biceps [2,3]. The origin is almost always traumatic, but some authors have described tendon degeneration due to bone abnormalities [1], mechanical conflict and partial tendons hypovascularity [4], Standard radiography eliminates a fracture or tearing at the bicipital tuberosity, which is exceptional. Only one case has been reported by Meherin and Kilgore [5]. Ultrasound is very effective at diagnosing according to a study by Weiss et al. [6]. MRI is an excellent examination that also assesses the integrity of the brachial biceps tendon, overlying muscle retraction and adjacent osteoarticular elements. To examine most of the tendon, the examination must be performed in the flexion-abduction-supination , obtained by performing a 90-degree bending of the elbow joint, a 180-degree abduction of the shoulder and a supination of the forearm [7].The treatment can be orthopedic, Morrey et al. [8] orthopedic treatment caused a $60 \%$ loss of strength for bending and supination. This treatment should be reserved for elderly patients with low functional demand. More generally, when the patient is active, athletic, young with high functional demand, the treatment must be surgical. It consists of attaching the distal tendon of the biceps to the bicipital tuberosity. Several attachment techniques have been published, yielding satisfactory results. The most common technique (performed in this clinical case) is to fix the biceps tendon through a single incision just below the level of the elbow on the bicipital tuberosity of the radius, using wires mounted on a screw anchor [7, 9], with good results [10] The other possible technique is a pathway first through two incisions (Boyd technique and Anderson [11]. The specific complications of this surgery vary depending on the technique used and include paresthesia in the radial nerve territory, postoperative pain, heterotopic ossifications, a limitation of pronosupination especially when the surgeon uses two pathways first passing between radius and ulna with a risk of radio-ulnar synostosis [12 13]. Postoperative rehabilitation is begun early after a short postoperative immobilization in flexion of varying duration depending on the surgical technique (between one and six weeks). In most cases, surgical treatment allows an integral recovery of muscle strength if it was managed early.

\section{CONCLUSION}

The rupture of the distal tendon of the brachial biceps muscle is a rare lesion. The clinical examination should have a pain in the bend of the elbow, especially in upset supination and an ascent of the muscular body 
that marks the diagnosis. Ultrasound should be performed quickly to confirm the diagnosis. Surgical treatment is surgical followed by short immobilization, then functional rehabilitation Prognosis is good in case of early and adapted management

\section{Conflict of interest}

The authors do not declare any conflict of interest

\section{REFERENCES}

1. Meyer JW, Boli J, Thomas GM, Ramirez FO. World society and the nation-state. American Journal of sociology. 1997 Jul;103(1):144-81.

2. Safran MR, Graham SM. Distal biceps tendon ruptures: incidence, demographics, and the effect of smoking. Clinical Orthopaedics and Related Research®. 2002 Nov 1;404:275-83.

3. Miyamoto RG, Elser F, Millett PJ. Distal biceps tendon injuries. JBJS. 2010 Sep 1;92(11):2128-38.

4. Seiler III JG, Parker LM, Chamberland PD, Sherbourne GM, Carpenter WA. The distal biceps tendon: two potential mechanisms involved in its rupture: arterial supply and mechanical impingement. Journal of shoulder and elbow surgery. 1995 May 1;4(3):149-56.

5. Meherin JM, Kilgore ES. The treatment of ruptures of the distal biceps brachii tendon. The American Journal of Surgery. 1960 May 1;99(5):636-40.

6. Weiss C, Mittelmeier M, Gruber G. Do we Need MR Images for Diagnosing Tendon Ruptures of the
Distal Biceps Brachii?. Ultraschall in der Medizin. 2000 Dec;21(06):284-6.

7. Giuffre BM, Moss MJ. Optimal positioning for MRI of the distal biceps brachii tendon: flexed abducted supinated view. American Journal of Roentgenology. 2004 Apr;182(4):944-6.

8. Morrey BF, Askew LJ, An KN, Dobyns JH. Rupture of the distal tendon of the biceps brachii. A biomechanical study. The Journal of bone and joint surgery. American volume. 1985 Mar;67(3):418-21.

9. Meherin JM, Kilgore ES. The treatment of ruptures of the distal biceps brachii tendon. The American Journal of Surgery. 1960 May 1;99(5):636-40.

10. Lintner S, Fischer T. Repair of the distal biceps tendon using suture anchors and an anterior approach. Clin Orthop. 1996;322:116-9.

11. Dobbie RP. Avulsion of the lower biceps brachii tendon: analysis of fifty-one previously unreported cases. Am J Surg. 1941; 51:662-83.

12. McKee MD, Hirji R, Schemitsch EH, Wild LM, Waddell JP. Patient-oriented functional outcome after repair of distal biceps tendon ruptures using a single-incision technique. J Shoulder Elbow Surg. 2005;14:302-306.

13. Kelly EW, Morrey BF, O’Driscoll SW. Complications of repair of the distal biceps tendon with the modified twoincision technique. J Bone Joint Surg. 2000;82A:1575-1581. 